\title{
ANALISIS KEPUASAN PASIEN TERHADAP PELAYANAN KESEHATAN PADA PESERTA BPJS (BADAN PENYELENGGARA JAMINAN SOSIAL) DAN NON BPJS DI RSUD GAMBIRAN KEDIRI JAWA TIMUR
}

\author{
${ }^{1}$ Romaji, S.KM., M.Kes. ${ }^{2}$ Latifatun Nasihah,SST.,M.Kes.
}

\begin{abstract}
Abstrak
Kepuasan pasien merupakan perasaan yang dirasakan setelah membandingkan antara harapan dengan kenyataan. Upaya pemenuhan kepuasan harus menyeluruh kepada semua pasien baik pasien BPJS maupun don BPJS yang berobat ke rumah sakit. Tujuan penelitian untuk mengetahui kepuasan pasien terhadap pelayanan kesehatan pada peserta BPJS dan Non BPJS di Ruang Nifas RSUD Gambiran Kediri Jawa Timur.

Desain penelitian adalah observasional analitik dengan metode cross sectional. Populasi Pasien rawat inap (post partum dan lainnya) dari peserta BPJS dan non BPJS dengan rata-rata 140 pasien/bulan dengan sampel 100 responden (50 BPJS dan 50 Non BPJS) diambil accidental sampling. Variabel bebas kepersertaan pasien dilihat dari BPJS Kesehatan dan Non BPJS dikumpulkan dengan kuesioner dan dianalisis dengan uji Wilcoxon.

Diketahui hampir seluruh responden kelompok BPJS puas terhadap pelayanan kesehatan yaitu 40 responden (80,0\%), hampir hampir seluruh responden kelompok Non BPJS puas terhadap pelayanan kesehatan yaitu 44 responden $(88,0 \%)$ dari total 50 responden dan ada perbedaan kepuasan antara pasien BPJS dan Non BPJS terhadap pelayanan kesehatan ( $\mathrm{p}=0,012>0,05$ Ho ditolak). Hal ini disebabkan adanya penilaian subyektif dari pasien.

Disimpulkan masih ada perbedaan kepuasan pasien antara peserta BPJS dan non BPJS. Disarankan agar pihak rumah sakit melakukan evaluasi kembali mengenai pelayanan yang diberikan.
\end{abstract}

Kata kunci : kepuasan pasien, peserta BPJS dan Non BPJS

\section{ABSTRACT}

The patients' satisfaction was a sense after comparing between expectation and reality. The efforts to fulfill the satisfaction should be totally either to BPJS or non BPJS patients who went to the hospital. The objective of this research was to know the patients' satisfaction towards BPJS or non BPJS patients' health service at partum room of Gambiran Regional Hospital Kediri, East Java.

The design of this research was observational analytics with cross-sectional approach. The population was 140 BPJS and non BPJS inpatients on average every month (postpartum patients and others), and 100 respondents (50 BPJS patients and 50 non BPJS patients) were taken as samples by accidental sampling technique. The independent variable was the patients' membership or non-membership of BPJS, collected from questionnaires and analyzed with Wilcoxon Test.

The research results were almost all BPJS patients or 40 respondents (80.0\%) felt satisfied of the health service, almost all non BPJS patients or 44 respondents (88.0\%) felt satisfied of the health service of toally 50 respondents, and there was a difference of the satisfaction between BPJS and non BPJS patients towards the health service $(p=0.012>$ 0.05 Ho was denied), it was because of the patients' subjective judgments.

The conclusion was that there was and there was a difference of the satisfaction between BPJS and non BPJS patients. The hospital was recommended to make reevaluation towards the service given.

Keywords: The patients' satisfaction, BPJS and non BPJS members 
Rumah sakit merupakan salah satu unit pelayanan kesehatan yang harus melayani semua masyarakat. Mulai 1 Januari 2014 ada perubahan dalam sistem pembiayaan kesehatan, seperti tercantum dalam Undang-Undang No. 40 Tahun 2004 tentang Sistem Jaminan Kesehatan Nasional (SJSN). Dalam pelaksanaanya dikenal dengan sistem JKN (Jaminan Kesehatan Nasional) yang diselenggarakan oleh Badan Penyelenggara Jaminan Sosial (BPJS) Kesehatan, dimana dalam memberikan pelayanan bekerjasama dengan fasilitas kesehatan yang ada di seluruh Indonesia. Salah satu indikator yang dapat digunakan untuk mengukur tingkat keberhasilan sistem adalah dengan menilai tingkat kepuasaan pasien peserta JKN (Christiani, 2016).

Permasalahannya adalah masih ada pasien yang belum puas. Dalam pengalaman sehari-hari ketidakpuasan pasien yang paling sering antara lain : keterlambatan pelayanan dokter dan perawat, dokter sulit ditemui, lamanya proses masuk rawat, keterbatasan obat dan peralatan, ketersediaan sarana (toilet, tong sampah) serta ketertiban dan kebersihan rumah sakit. Banyaknya complain dan penilaian yang kurang baik dari peserta BPJS terhadap kualitas pelayanan kesehatan membuat konsumen merasa tidak puas. Mulai dari sistem yang berbelit-belit, tidak ada batasan pembiayaan yang jelas, pembatasan obat bahkan pelayanan yang dinilai lama terhadap peserta BPJS (Murtiana, 2016).

Penelitian sebelumnya seperti survei di Rumkital Dr. Ramelan Surabaya, dari 30 pasien pengguna BPJS, sebanyak 27 pasien kurang puas tentang ketentuan dan persyaratan yang ditetapkan BPJS, adanya pembatasan sarana prasarana seperti penarikan biaya saat memasuki IGD, adanya ketentuan beberapa pelayanan kesehatan yang tidak dijamin BPJS serta keluhan terlalu lama waktu yang diperlukan untuk mengurus persyaratan BPJS saat berobat, dimana dulu bisa langsung menuju poli klinik tetapi sekarang lebih lama (Ningrum, 2014).

Demikian juga dari penelitian Sari (2015) menyebutkan bahwa secara umum kepuasan antara pasien BPJS dan pasien umum untuk rerata tingkat kepuasan pasien umum sebesar 106,14 sedangkan pasien BPJS hanya 66,62. Peneliti menyimpulkan rerata skor tingkat kepuasan pasien umum lebih tinggi dibandingkan dengan pasien BPJS. Nilai p (sig) sebesar 0,001 telah memenuhi kriteria normal yaitu $\mathrm{p}<0,05$, sehingga didapatkan perbedaan kepuasan yang bermakna antara pasien BPJS dan Non BPJS. Penelitian Yuniar (2016) juga menunjukkan hal yang sama yaitu sebagian pasien BPJS merasa kurang puas terhadap "semua obat dalam resep masuk dalam tanggungan biaya BPJS" dan "Ketersediaan semua obat dalam resep yang ditanggung BPJS di apotek".

Kondisi serupa bisa juga terjadi di rumah sakit lain termasuk Rumah Sakit Umum Gambiran Kota Kediri. Hasil penelitian sebelumnya oleh Yosi Arum Ariningtyas, Purnomo Suryantoro, Mufdlilah (2017) di Ruang Bersalin RSUD Gambiran Kota Kediri, hampir seluruh responden BPJS termasuk puas terhadap pelayanan kebidanan yaitu 38 responden $(95 \%)$ dari total 40 responden, akan tetapi masih ada 2 pasien (5\%) yang merasa cukup puas. Hal ini memberikan gambaran bahwa belum seluruh pasien belum merasa puas terhadap pelayanan yang diterima dari RSUD Gambiran Kota Kediri.

Banyak faktor yang dapat mempengaruhi kepuasan pasien, diantaranya adalah persepsi, latar belakang sosial-ekonomi, norma, pendidikan, budaya, kepribadian kustomer bersangkutan (Rewansyah dalam Mulyawan, 2016). Ada dua aspek yang mempengaruhi kepuasan pasien yakni aspek pelanggan (umur, jenis kelamin, pendidikan, dan lain-lain) dan aspek pelayanan kesehatan (aspek medis, seperti tersedianya peralatan yang memadai, dan aspek non medis yang mencakup layanan petugas kesehatan, kenyamaan dan kebersihan ruang tunggu, serta biaya yang murah (Yuniar, 2016). Faktor lain demografi pasien (umur, jenis kelamin, status sosial, pendidikan) (Christasani, 2016). Faktor lain jenis kepersertaan pasien (BPJS dengan umum) (adanya sistem rujukan berjenjang, pelayanan lebih lama berkaitan dengan waktu antrian panjang) (Sari, 2015), alur yang berbeda maka antrian berlangsung lama (Megawati, dkk., 2016).

Kualitas pelayanan juga dapat mempengaruhi kepuasan pasien (yang dapat dibedakan antara pasien BPJS dengan Non BPJS). Kualitas pelayanan yang baik akan menimbulkan kepuasan pada pelanggan atau pengguna jasa layanan (pasien) dan mempunyai hubungan yang positif dan signifikan dengan tingkat kepuasan pasien (Wahyuni, 2015). Dampak dari kepuasan pasien terhadap pelayanan kesehatan akan mempengaruhi jumlah kunjungan di unit pelayanan kesehatan termasuk rumah 
sakit. Apabila pasien tidak puas (misal menunggu terlalu lama, "provider" kurang ramah, ketrampilannya juga kurang), maka akan membuat pasien kecewa. Faktor kepuasan pasien juga dapat menciptakan persepsi masya-rakat tentang citra rumah sakit (Wirijadinata dalam Antina, 2016).

Mengingat permasalahan di atas maka harus segera dilakukan upaya perbaikan mutu pelayanan kesehatan termasuk bagi peserta BPJS. Untuk itu BPJS Kesehatan, berdasarkan Pasal 83 Peraturan BPJS Kesehatan No. 1 Tahun 2014 tentang Penyelenggaraan Jaminan Kesehatan, harus melakukan kendali mutu melalui salah satunya adalah pemenuhan standar mutu fasilitas kesehatan dan proses pelayanan kesehatan. Fasilitas kesehatan (rumah sakit) juga dituntut memberikan pelayanan kesehatan paripurna (Pasal 57 Peraturan BPJS Kesehatan No.1 Tahun 2014) dengan memperhatikan mutu pelayanan (Pasal 42 Peraturan Presiden No. 12 Tahun 2013 tentang Jaminan Kesehatan). Secara teknis peran petugas kesehatan dapat diwujudkan melalui kinerjanya berupa kecepatan, kemudahan dan kenyamanan. Petugas memberikan jasa pengobatan yang cepat, memenuhi kebutuhan pasien dan kenyamanan dengan memperhatikan kebersihan, keramahan dan kelengkapan (Nursalam, 2013). Tujuan dari penelitian ini adalah untuk mengetahui kepuasan pasien terhadap pelayanan kesehatan pada peserta BPJS (Badan Penyelenggara Jaminan Sosial) dan Non BPJS di Ruang Nifas RSUD Gambiran Kediri Jawa Timur.

\section{METODE}

Penelitian ini menggunakan rancangan observasional analitik yang dilakukan dengan metode cross sectional. Lokasi dalam penelitian ini adalah di RSUD Gambiran Kota Kediri Jawa Timur. Waktu penelitian dilaksanakan bulan Agustus 2018. Variabel bebas adalah kepersertaan pasien dilihat dari BPJS yaitu BPJS Kesehatan dan Non BPJS atau pasien umum dapat berupa peserta asuransi swasta atau sama sekali tidak memiliki asuransi dikumpulkan dengan kuesioner. Analisis statistik dilakukan dengan menggunakan teknik statistik wilcoxon.

\section{HASIL}

Penelitiqan ini dengan sampel 100 responden. Hasil analisis univariate didapatkan hampir seluruh responden pada kelompok BPJS termasuk puas terhadap pelayanan kesehatan yaitu sebanyak 40 responden $(80,0 \%)$ dari total 50 responden, hampir seluruh responden pada kelompok Non BPJS termasuk puas terhadap pelayanan kesehatan yaitu sebanyak 44 responden $(88,0 \%)$ dari total 50 responden.

Hasil analisis bivariate didapatkan hasil pada responden kelompok BPJS hampir seluruhnya puas yaitu 40 responden $(80 \%)$ dan pada Non BPJS didapatkan hampir seluruhnya puas yaitu sebanyak 44 responden (88\%) dan ada perbedaan tingkat kepuasan antara pasien peserta BPJS dan Non BPJS terhadap pelayanan kesehatan di RSUD Gambiran Kediri ( $p=0,012>$ 0,05 maka Ho ditolak).

\section{PEMBAHASAN}

\section{a. Tingkat Kepuasan Pasien terhadap Pelayanan Kesehatan Pasien BPJS}

Berdasarkan tabel 4.2 diketahui hampir seluruh responden dari kelompok asuransi BPJS termasuk puas terhadap pelayanan kesehatan yaitu sebanyak 40 responden $(80 \%)$ dari total 50 responden.

Kepuasan menurut Oliver dalam (Sari, 2008) merupakan tingkat perasaan seseorang (pelanggan) setelah membandingkan antara kinerja atau hasil yang dirasakan (pelayanan yang diterima dan dirasakan) dengan yang diharapkan. Selanjutnya Rahmayanty (2013) mendefinisikan kepuasan pasien adalah evaluasi positif dari dimensi pelayanan yang beragam yang diberikan pemberi jasa pelayanan. Kepuasan adalah tingkat perasaan seseorang (pelanggan) setelah membandingkan antara kinerja atau hasil yang dirasakan (pelayanan yang diterima dan dirasakan) dengan yang diharapkannya (Sari, 2008). Wijono dikutip Nugroho (2009) mengungkapkan kepuasan pelanggan rumah sakit atau organisasi pelayanan kesehatan lain atau kepuasan pasien dipengaruhi banyak faktor antara lain pendekatan dan perilaku petugas, mutu informasi, prosedur perjanjian, waktu tunggu, fasilitas umum yang tersedia, fasilitas perhotelan untuk pasien seperti mutu makanan, pengaturan kunjungan dan "privasi" outcome terapi dan perawatan yang diterima. Selain itu juga dipengaruhi oleh faktor jenis kelamin, usia pasien, pendidikan, kominiksai terapeutik, sikap dan pendekatan stap, kualitas pelayanan (Budiastuti dalam Liestriana, 2010).

Hasil penelitian menunjukkan hampir seluruh responden dari kelompok BPJS termasuk puas terhadap pelayanan kesehatan. Hal ini dapat disebabkan oleh berbagai faktor. Mengacu kepada teori yang ada bahwa kepuasan akan terwujud jika 
pelanggan atau pasien mendapatkan pelayanan sesuai atau melebihi dari keinginan atau harapannya. Umumnya pasien datang mengharapkan adanya pelayanan yang cepat, petugas ramah dalam memberikan pelayanan, penampilan fisik terlihat baik, bersih, rapi dan meyakinkan serta dapat dipercaya, terkesan memiliki keahlian dan pengetahuan yang sesuai dengan kebutuhan pasien, juga pasien merasa mudah dalam mendapatkan pelayanan apapun, secara etika petugas juga terlihat sopan, ada rasa hormat serta ada kesungguhan dalam melayani pasien. Kesan seperti ini merupakan hal pertama yang terekam pasien yang dapat berpengaruh terhadap kepuasan pasien. Berbagai dimensi tersebut sesuai hasil penelitian ternyata sudah di dapatkan pasien, termasuk saat ini pasien juga merasa bahwa ruang pelayanan atau ruang rawat inap di rumah Gambiran sudah sangat bagus, bersih, rapi, luas, akses mudah dan berbagai kelebihan lainnya. Sebagai contoh untuk penilaian "Keadaan ruang rawat inap sudah terlihattertata rapi dan bersih", dari 50 pasein BPJS yang mengatakan puas sebanyak 41 responden $(82 \%)$ bahkan ada 7 pasien (14\%) mengatakan sangat puas. Untuk kecepatan pelayanan misalnya "Prosedur penerimaan pasien dilakukan secara cepat dan tidak berbelit-belit", dari 50 pasien BPJS yang sudah puas sebanyak 34 responden (68\%) dan yang sangat puas ada 11 responden (22\%). Untuk pernyataan "Dokter/Perawat/Bidan bersikap ramah dansopan", dari 50 pasien yang mengatakan puas sebanyak 37 pasien $(74 \%)$ dan yang sangat puas sebanyak 11 pasien (22\%). Untuk "keamanan dan kenyamanan pasien selama di rumah sakit terjamin karena ada dokter umum dan dokter spesialis", dari 50 pasien yang mengatakan puas sebanyak 40 pasien $(80 \%)$ dan yang sangat puas sebanyak 8 pasien (16\%). Berikutnya "dokter/perawat/bidan dan tenaga penunjang mempunyai sikap dan perilaku yang baik", dari 50 responden yang mengatakan puas sebanyak 40 pasien $(80 \%)$ dan yang sangat puas sebanyak 9 pasien (18\%). Beberapa indikator ini terlihat sama untuk indikator lainnya sehingga secara umum dapat diinterpretasikan bahwa mayoritas pasien sudah puas.

Terwujudnya kesan tersebut tidak terlepas dari peran BPJS yang selama ini sebagai pihak ketiga dalam asuransi kesehatan. BPJS berwenang memberikan kontrol kepada pihak PPK (Pemberi Pelayanan Kesehatan) termasuk rumah sakit sebagai mitra kerjanya dan kewenangan ini juga sudah dilaksanakan secara baik. Monitoring dan evaluasi selama ini sudah jalan disamping adanya hotline service yang bisa dihubungi klien/pasien peserta BPJS. Adanya keluhan pasien yang sampai kepada pengelola BPJS akan menjadi bahan masukan kepada pihak PPK. Oleh karenanya pada saat ini banyak pihak PPK (puskesmas, rumah sakit, dokter keluarga) sudah memberikan pelayanan yang berkualitas sehingga mendekati harapan pelanggan (pasien).

Disamping faktor dari provider tersebut, masalah keinginan dan harapan pada dasarnya merupakan masalah yang sifatnnya subyektif. Oleh karenanya penilaian mengenai pemenuhan harapan juga sangat subyektif dan sangat tergantung dari penilaian subyektif pelanggan/pasien. Subyektifitas itu sendiri sangat dipengaruhi oleh karakteristik masing-masing orang, mulai dari latar belakang usia, pendidikan, pekerjaan, penghasilan maupun faktor yang lain. Berdasarkan hasil analisis diketahui hampir seluruh responden kelompok BPJS berusia >35 tahun. Dapat diinterpretasikan bahwa usia tersebut tergolong sebagai usia yang sudah dewasa dan cukup matang, sehingga mampu menempatkan diri dalam terhadap pelayanan yang ada dan tidak terlalu menuntut pelayanan yang lebih dari petugas.

Faktor lain yang berpengaruh terhadap kepuasan pasien adalah latar belakang pendidikan. Teori menjelaskan bahwa tingkat pendidikan akan cenderung mambantu seseorang dalam melakukan penilaian terhadap suatu materi atau objek. Berdasarkan hasil penelitian sebelumnya bahwa responden dengan tingkat pendidikan rendah akan merasa lebih puas. Berdasarkan hasil analisis diketahui hampir setengah responden kelompok BPJS berpendidikan SMA. Hal ini dapat diinterpretasikan dengan jenjang pendidikan SMA maka jenjang pendidikannya tidak terlalu tinggi sehingga standar tuntutan akan pelayanan juga tidak teerlalu tinggi, sehingga pelayanan yang diterima sudah dirasakan dapat memenuhi harapan atau bahkan melebihi harapannya.

Faktor lain yang dapat berpengaruh terhadap kepuasan pasien adalah latar belakang pekerjaan. Berdasarkan hasil analisis diketahui hampir setengah responden kelompok BPJS sebagai ibu rumah tangga. Sebagai ibu rumah tangga dapat diasumsikan pada umumnya memiliki keterbatasan pengetahuan, wawasan, tuntutan akan pelayanan yang sangat berkualitas. Dapat diinterpretasikan bahwa pelayanan yang diterima pada akhirnya sudah dapat memuaskan pelanggannya. 


\section{b. Tingkat Kepuasan Pasien terhadap Pelayanan Kesehatan Pasien Non BPJS}

Berdasarkan tabel 4.3 diketahui hampir seluruh responden dari kelompok Non BPJS termasuk puas terhadap pelayanan kesehatan yaitu sebanyak 44 responden (88\%) dari total 50 responden.

Sebagaimana telah diuraikan di atas bahwa pada prinsipnya kepuasan itu adalah tingkat perasaan seseorang (pelanggan) setelah membandingkan antara kinerja atau hasil yang dirasakan (pelayanan yang diterima dan dirasakan) dengan yang diharapkan. Rahmayanty (2013) juga mendukung definisi kepuasan pasien dengan menyatakan bahwa kepuasan itu merupakan evaluasi positif dari dimensi pelayanan yang beragam. dengan Wijono yang dikutip Nugroho (2009) menyatakan bahwa kepuasan pelanggan di rumah sakit atau organisasi pelayanan kesehatan lainnya dipengaruhi banyak faktor antara lain pendekatan dan perilaku petugas, mutu informasi, prosedur perjanjian, waktu tunggu, fasilitas umum yang tersedia, fasilitas perhotelan untuk pasien seperti mutu makanan, pengaturan kunjungan dan "privasi" outcome terapi dan perawatan yang diterima. Selain itu juga dipengaruhi faktor jenis kelamin, usia pasien, pendidikan, kominiksai terapeutik, sikap dan pendekatan stap, kualitas pelayanan (Budiastuti dalam Liestriana, 2010).

Jika hasil penelitian menunjukkan hampir seluruh responden dari kelompok Non BPJS termasuk puas terhadap pelayanan kesehatan, maka hal ini juga dapat disebabkan oleh berbagai faktor. Pasien non BPJS umumnya mampu membayar sendiri biaya pelayanan kesehatan. Mereka bebas memilih kelas pelayanan yang disediakan sesuai kemampuannya. Umumnya dengan beban harus mengeluarkan biaya seperti ini maka mereka menuntut adanya pelayanan yang baik atau yang bermutu. Disisi lain petugas kesehatan juga merasa bahwa pasien yang dilayani adalah orang yang mampu yang dapat membayar secara langsung atas biaya pelayanan kesehatan. Secara psikologis akan memberikan dampak tersendiri bagi provider untuk memberikan pelayanan terbaiknya bahkan jika mungkin juga berlebih. Tidak heran jika selama ini ada asumsi di masyarakat bahwa pelayanan bagi pasien non BPJS akan lebih baik jika dibandingkan dengan pasien BPJS.

Mengingat hal tersebut di atas maka dapat diasumsikan bahwa bagi pasien non BPJS akan cenderung bisa mendapatkan pelayanan yang sesuai atau bahwa melebihi dari keinginan atau harapannya. Namun demikian pada umumnya pasien non BPJS juga mengharapkan adanya pelayanan yang lebih baik yaitu pelayanan cepat, tepat, konsistensi, termasuk fasilitas atau sarana dan prasarana atau penampilan secara fisik terlihat meyakinkan, petugas memiliki pengetahuan yangbaik, mudah dalam mendapatkan pelayanan, selalu dilayani dengan sopan, ramah tamah dan hormat kepada pasien, adanya kesungguhannya dalam memberikan pelayanan dan berbagai tuntutan lainnya. Hasil penelitian menunjukkan untuk "keadaan ruang rawat inap sudah terlihat tertata rapi dan bersih", dari 50 pasein BPJS yang mengatakan puas sebanyak 34 responden (68\%) bahkan ada 4 pasien (8\%) mengatakan sangat puas. Untuk kecepatan pelayanan misalnya "prosedur penerimaan pasien dilakukan secara cepat dan tidak berbelit-belit", dari 50 pasien BPJS yang sudah puas sebanyak 34 responden (68\%) dan yang sangat puas ada 11 responden (22\%). Untuk pernyataan "dokter/perawat/bidan bersikap ramah dan sopan", dari 50 pasien yang mengatakan puas sebanyak 32 pasien (64\%) dan yang sangat puas sebanyak 4 pasien $(4 \%)$. Untuk "keamanan dan kenyamanan pasien selama di rumah sakit terjamin karena ada dokter umum dan dokter spesialis", dari 50 pasien yang mengatakan puas sebanyak 35 pasien (70\%) dan yang sangat puas sebanyak 3 pasien (6\%). Berikutnya "dokter/perawat/bidan dan tenaga penunjang mempunyai sikap dan perilaku yang baik", dari 50 responden yang mengatakan puas sebanyak 40 pasien $(80 \%)$ dan yang sangat puas sebanyak 1 pasien (2\%). Beberapa indikator ini terlihat sama untuk indikator lainnya sehingga secara umum dapat diinterpretasikan bahwa mayoritas pasien sudah puas.

Disamping faktor di atas terwujudnya kepuasan pasien non BPJS juga terkait dengan karakteristik masing-masing pasien, mulai dari latar belakang usia, pendidikan, pekerjaan, penghasilan maupun faktor yang lain. Berdasarkan hasil analisis diketahui sebagian besar responden kelompok BPJS berusia 20-35 tahun. Dapat diinterpretasikan bahwa usia responden sudah cukup matang dan dewasa sehingga tuntutan akan pelayanan juga sudah sangat baik dalam arti wajar, sehingga apa yang diharapkan dari petugas juga wajar, sehingga dari pelayanan yang diterima saat ini sudah dinilai memenuhi harapannya sehingga pasien merasa puas.

Faktor lain yang berpengaruh terhadap kepuasan pasien adalah latar belakang pendidikan. Tingkat pendidikan akan cenderung mambantu 
seseorang dalam melakukan penilaian terhadap suatu materi atau objek. Berdasarkan hasil penelitian sebelumnya didapatkan bahwa responden dengan tingkat pendidikan lebih rendah akan merasa lebih puas. Berdasarkan hasil analisis diketahui setengah responden kelompok non BPJS juga berpendidikan SMA. Hal ini dapat diinterpretasikan bahwa jenjang pendidikan responden juga tidak terlalu tinggi sehingga standar tututan mutu pelayanan juga tidak terlalu tinggi. Oleh karenanya pelayanan yang diberikan kepada peserta non BPJS sudah dirasakan dapat memenuhi harapan semua pelanggan atau bahkan melebihi harapan mereka. Oleh karenanya meskipun dengan perbedaan latar belakang pendidikan yang ada, mereka sama-masa merasakan telah mendapatkan pelayanan yang baik dan sudah sesuai dengan harapan atau kebutuhannya.

Faktor lain yang dapat berpengaruh terhadap kepuasan pasien adalah latar belakang pekerjaan. Berdasarkan hasil analisis diketahui sebagian besar responden kelompok non BPJS juga sebagai ibu rumah tangga. Hal ini disebabkan dengan pekerjaan sebagai ibu rumah tangga umumnya memiliki keterbatasan penghasilan.. Pada umummya akan berimplikasi terhadap besarnya tuntutan akan pelayanan kesehatan yang baik. Terbukti berdasarkan hasil analisis diketahui hampir seluruhnya juga puas. Dapat diinterpretasikan bahwa pelayanan dapat memuaskan semua golongan ekonomi dari pasien non BPJS.

\section{c. Perbedaan Tingkat Kepuasan antara Pasien BPJS dan Non BPJS}

Berdasarkan tabel 4.5 diketahui ada perbedaan kepuasan pasien terhadap pelayanan kesehatan pada peserta BPJS (Badan Penyelenggara Jaminan Sosial) dan Non BPJS di Ruang Nifas RSUD Gambiran Kediri Jawa Timur (Wilcoxon $\mathrm{p}=0,012<0,05$ maka Ho ditolak).

Badan Penyelenggara Jaminan Sosial atau (BPJS) merupakan lembaga yang dibentuk untuk menyelenggarakan program jaminan sosial di Indonesia menurut Undang-undang Nomor 40 Tahun 2004 dan Undang-undang Nomor 24 Tahun 2011.Sesuai Undang-undang Nomor 40 Tahun 2004 tentang Sistem Jaminan Sosial Nasional, BPJS merupakan badan hukum nirlaba. Pasien BPJS berarti pasien yang sudah terdaftar program jaminan sosial di Indonesia. Dalam kontek ini pasien BPJS berbeda dengan non BPJS dilihat dari aspek pembiayassan kesehatan. Dalam pasien medis kedua jenis pasien ini adalah sama sehingga harus mendapatkan pelayanan yang sama. Oleh karenanya petugas kesehatan harus tetap bekerja secara profesional. Dalam penelitian Burhan (2014), sebagai panduan dalam menilai profesionalisme, Arnold dan Stern (2006) memberikan definisi bahwa profesionalisme ditunjukkan melalui sebuah dasar kompetensi klinis, kemampuan berkomunikasi, pemahaman etika dan hukum yang dibangun oleh harapan untuk melaksanakan prinsip profesionalisme.

Ada perbedaan kepuasan pasien terhadap pelayanan kesehatan pada peserta BPJS (Badan Penyelenggara Jaminan Sosial) dan Non BPJS disebabkan adanya penilaian subyektif dari pasien. Sebenarnya petugas kesehatan sudah tidak membeda-bedakan pasien dalam memberikan pelayanan. Apapun jenis pasien (BPJS ataupun Non BPJS) semua akan diperlakukan sama, dilayani dengan sama, yakni sama-sama cepat, sama-sama mendapatkan fasilitas fisik atau sarana dan prasarana yang sama baiknya sesuai dengan kelasnya, sama jenis obat yang diberikan yang sesuai standar yang telah ditetapkan BPJS, ruang rawat inap juga sama, keramahan petugas dalam memberikan pelayanan juga sama, dan semua pendukung yang lainnya juga sama. Namun demikian dari hasil wawancara dengan pasien saat pengambilan data, ada pasien yang merasa bahwa untuk pasien BPJS terkadang terkesan lama dalam pelayanan tertentu, misalnya jadwal operasi bagi pasien BPJS sering di undur sehingga memberi kesan untuk pasien BPJS sering di buat lama, berbeda dengan pasien Non BPJS yang selalu tepat waktu.

Sebenarnya saat ini petugas kesehatan juga tidak berani membedakan kualitas dalam pelayanan. Monitoring dan evaluasi pelayanan sudah dilaksanakan secara periodik kepada PPK (pemberi pelayanan kesehatan) atau kepada provider (petugas kesehatan) oleh pihak BPJS. Dalam arti peserta BPJS dijamin kualitas pelayanan yang akan diterima sama dengan pasien non BPJS. Petugas BPJS dengan ketat memberikan persyaratan sarana dan prasarana yang harus dipenuhi PPK (pemberi pelayanan kesehatan) bagi pasien BPJS. Adanya persyaratan demikian ini maka pasien akan sama-sama merasa puas terhadap pelayanan yang diterima.

\section{PENUTUP}

Penelitian ini didapatkan hasil bahwa 1) hampir seluruh responden pada kelompok BPJS termasuk puas terhadap pelayanan kesehatan yaitu sebanyak 40 responden $(80,0 \%)$ dari total 50 responden., 2)hampir hampir seluruh responden pada 
kelompok Non BPJS termasuk puas terhadap pelayanan kesehatan yaitu sebanyak 44 responden $(88,0 \%)$ dari total 50 responden, 3$)$ ada perbedaan tingkat kepuasan antara pasien peserta BPJS dan Non BPJS terhadap pelayanan kesehatan di RSUD Gambiran Kediri ( $\mathrm{p}=0,012>0,05$ maka Ho ditolak). Saran yang peneliti berikan kepada RSUD Gambiran agar tetap berusaha memberikan pelayanan terbaik kepada semua pasien baik peserta BPJS maupun non BPJS. Senantiasa melakukan peningkatan kualitas pelayanan mulai dari sarana, prasarana, staff dan tenaga kesehatan agar tercapai pelayanan kesehatan yang memuaskan. Sedangkan kepada BPJS agar selalu mengontrol kinerja petugas kesehatan selaku PPK (Pemberi Pelayanan Kesehatan) dalam memberikan pelayanan. Selalu merespon dengan cepat umpan balik dari pelanggan jika ada keluhan yang disampaikan.

\section{DAFTAR PUSTAKA}

Burhan, Fatmadina. (2014). Penilaian terhadap Profesionalisme Dokter di Unit RawatJalan RSUP Haji Adam Malik Medan. Skripsi untuk Memperoleh Sarjana Kedokteran Universitas Sumatra Utara Medan: Diterbitkan di 123dok.com

Liestriana. 2010. Hubungan Komunikasi Terapeutik dengan Kepuasan Pasien Pasca Operasi Rawat Inap di RSUD Kajen Kabupaten Pekalongan.

Nugroho, Haryanto Adi \& Septyani Aryati. 2009. Hubungan antara Komunikasi Terapeutik Perawat dengan Kepuasan Pasien di Rumah Sakit lslam Kendal. FIKkUS Jurnal Keperawatan Vol. 2 No. 2 Maret 2009 : 36-41

Rahmayanty, Nina. (2013). Manajemen Pelayanan Prima (Mencegah Pembelotan dan Membangun Customer Loyality. Yogyakarta: Grahallmu

Sari, Irine Diana. (2008). Manajemen Pemasaran Usaha Kesehatan. Yokyakarta: Mitra Cendikia Press 